\title{
Wind Power Impact on Power System Frequency Response
}

\author{
H.R. Chamorro, Student Member, IEEE, M. Ghandhari, Member, IEEE and R. Eriksson, Member, IEEE
}

\begin{abstract}
The use of high power electronics in the large scale integration of wind power in the transmission and distribution systems can affect the system inertia response and the ability to recover frequency stability after large disturbances. Different approaches have been presented to show the system dynamic behaviour, and to quantify the wind power impact on the system inertial and frequency response. This paper gives a short overview of studies performed regarding the system inertia issues under high penetrations of wind power. Also, it presents the results of a case study to show how the system inertia can be affected by high penetrations of wind power.
\end{abstract}

Keywords - Wind Power, Inertial Response, Frequency Deviation, Power Systems, Frequency Control, Voltage Source Converter.

\section{INTRODUCTION}

Recent investments and initiatives around the world have been promoting the application of Renewable Energy Sources (RES) to reduce the pollutant carbon dioxide emissions and the global warming. In particular, wind power has been sponsored widely contributing to the energy pool with a growing generation proportion capacity installed around the world [1], and substituting central power plants by large offshore wind farms [2]. As a result of the increasing use of RES, some operational challenges must be kept in mind in order to not affect the system stability. One of these challenges is the analysis and advances of grid rules or technical code requirements regarding the improvement of dynamic support to the grid, and an adequate frequency response provision [3].

This current change in the power system requires different planning and operation strategies in order to provide enough technical and regulatory policies to do not diminish or affect the growing power demands [4]-[5].

Several emerging grid connection codes have included many technical conditions and requirements looking for a suitable integration of wind power, allowing feed the increasing demand and making compatible with the frequency margins and protection systems available of the grid [6].

The frequency control in a power system after a large disturbance is performed in different stages and time frames. The first stage is due to an inherent action named inertial frequency response which takes energy from the rotating masses to oppose a frequency deviation from the scheduled frequency.

Harold R. Chamorro is a PhD student at KTH Royal Institute of Technology, Stockholm, Sweden (e-mail: hr.chamo@ieee.org, hrcv@kth.se)

Mehrdad Ghandhari is Professor at KTH Royal Institute of Technology, Stockholm, Sweden (e-mail: mehrdad@kth.se)

Robert Eriksson is a Postdoctoral researcher at KTH Royal Institute of Technology, Stockholm, Sweden (e-mail: robert.eriksson@ee.kth.se )
In the next stage the automatic governing systems will be activated to keep the frequency deviation at an acceptable level (primary control). Then, the secondary control is performed to restore the used reserves, and the system frequency to its scheduled value.

The large scale penetration and integration of variable speed wind energy has a significant impact on the system inertia. This is due to use of power electronic converters [7], for instance back-to-back Voltage Source Converters (VSC), isolating the wind turbines from the power system and making them insensitive to any change in the system frequency and consequently unable to provide any inertial response [8]-[10]. Furthermore, to get the maximum power from wind power plants Maximum Power Point Tracking (MPPT) algorithm is used, so that wind turbines can hardly contribute to the frequency control [11]-[12].

The North American Electric Reliability Corporation (NERC) in [13], has reported the declining of the frequency response and inertia due to the inverter interfaced generation, and has proposed the use of the synthetic inertia as a potential solution to it. The so called synthetic inertia is a local automatic controller included in wind turbines with a time frame of some seconds.

The European Wind Energy Association (EWEA) in [14], suggests the establishment of a systematic system planning to integrate wind power, and promotes to understand the dynamic interaction of the system and wind power.

Hydro-Québec TransÉnergie (HQT) has exposed the need for frequency support by wind power in [15], and proposes a method for synthetic inertia in order to maintain the actual system performance.

Electric Reliability Council of Texas (ERCOT) transmission studies have evidenced a reduction in dynamic frequency response on the conventional generation due to the increasing wind power generation during the last five years [16]. Their analysis has shown that the replacement of the conventional generation (synchronous generators) by high wind generation in service resulted in less system inertia in the system [17].

Another report, [18], has studied the frequency response in California and the impact of the current projections of high integration of wind power on the system. It proposes different performance metric factors to measure the frequency performance by wind turbines, some of which are used in this paper. A more detailed discussion regarding the inertial frequency response and the impact of wind farms on the system frequency response can be found in [19]-[23].

In conventional generation the primary and secondary control reserves have to be enough to tolerate the loss of any single component and recover the margins stability, however 
with the inclusion of wind power, the margins of frequency deviation can be out of the acceptable region provoking failures in the generators tripping limits [11]. An appropriate response from the primary and secondary controllers can fulfil the frequency margins and assure a correct compensation of the frequency deviation in the system [24]-[25].

Although application of power electronics (such as VSCs) and their corresponding controllers to integration of wind power in the system are the main reason why wind power turbines are unable to contribute to the system inertial frequency response, VSCs enable however the wind turbines to capture the wind power at different speeds and permit very flexible control of active and reactive power in cases of normal and disturbed grid conditions [26]. The incorporation of VSC control loops to regulate and manage the active and reactive power to improve system stability has been reported in [27]-[29], and a coordination strategy to transfer power from wind power to different connecting points in order to enhance the system operation has been discussed in [30]-[31].

In Multi Terminal High Voltage Direct Current (MTHVDC) system to which wind farms are connected, frequency coordination control plays a key role to manage the power sharing in the converters [32]. In [33] a coordination method to improve the inertial response and primary frequency, applying synthetic inertia has been presented.

This paper is structured as follows: In Section II an overview of inertia concept is given. Sections III presents some case studies regarding the impact of wind power on the system frequency of a test system. Finally, the conclusions and future work of this research are given in Section IV and Section V.

\section{SYSTEM DYNAMIC RESPONSE}

As it was stated previously, the frequency control in a power system after a large disturbance is performed in different stages and time frames, namely inertia frequency, primary control and secondary control.

In this section the inertial response and primary control are discussed. .

\section{A. Inertial Response}

Inertial response is inherent in the system due to rotating mass of machines synchronously connected providing counter response within seconds to oppose the frequency deviation following a loss of generation [17], [34].

In a synchronous system, in case of losing a generating unit, the frequency drops because of the imbalance between generation and load. This is reflected in the power system instantaneously. During the first period, the inertial response of the spinning machines in the entire system, reacts releasing or storing kinetic energy tending to reduce the frequency deviation [35]-[36]. System inertia is defined as the total amount of kinetic energy stored in all rotating masses.

The inertial constant of an individual generator can be interpreted as the time that generator can provide full output power from its own stored kinetic energy, taking values between 2 to 9 seconds. It is defined by

$$
H_{i}=\frac{1}{2} \frac{J_{i} \omega_{0}^{2}}{S_{i}}
$$

where, $J_{i}$ is the total moment of inertia, $S_{i}$ is the rated power of generator $i, \omega_{0}=2 \pi f_{0}$ and $f_{0}$ is the nominal frequency $(\mathrm{Hz})$.

The total amount of the stored kinetic energy in the system is the sum of the kinetic energy of all single machines:

$$
S H=\sum_{i} S_{i} H_{i}
$$

Then the dynamic of the system frequency in the Centre of Inertia (COI) reference frame is given by:

$$
\frac{d f}{d t}=\frac{1}{2} \frac{\Delta P}{S H} f_{0}
$$

where,

$\mathrm{SH}$ is the total stored kinetic energy (Ws)

$d f / d t$ is the rate of change of frequency $(\mathrm{Hz} / \mathrm{s})$

$\Delta P$ is the power change $(\mathrm{W})$

Thus, the system inertial response can be determined by

$$
S H=\frac{1}{2} \frac{\Delta P}{(d f / d t)} f_{0}
$$

\section{B. Frequency Response}

Beyond the inertial response, the frequency is stabilized and then restored to the nominal frequency by the primary (governor action) and secondary controllers, respectively.

Primary control acts as a proportional controller avoiding high frequency deviations; however a steady state error is still remained. The response of this control is given in seconds $(<30$ s) [37]-[38].

Secondary control returns the frequency back to its nominal value and also restores the reserves; its deployed time frame is given in minutes [38].

\section{Synthetic Inertia}

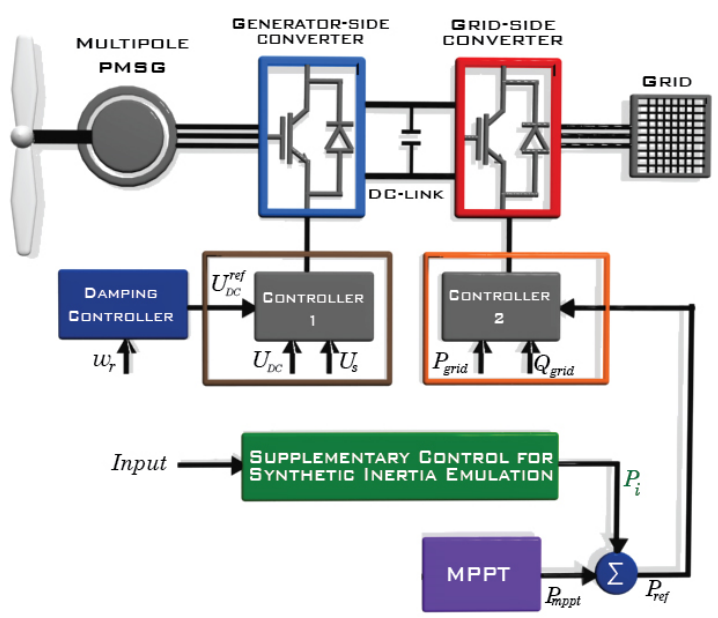

Fig. 1 Full Converter and Synthetic Inertia

Fig 1 shows the connection of a Permanent Magnet Synchronous Generator (PMSG) wind turbine to a grid via backto-back VSC. The figure also shows the corresponding controller of the converters where $P_{i}$ is the output of a supple- 
mentary control to add a synthetic inertial response by the wind turbine.

The synthetic inertial response is an efficient way to contribute to the system inertia [39]-[41]. Different control proposals have been used to mimic the inertia; some of them add a derivative term of frequency in the droop control loops equations [33], [42]. One related proposal uses this signal to enhance the primary frequency control adjusting the power curve reducing frequency changes following disturbances [43].

One report by NREL, [44], presents how wind farms can contribute to diminish the frequency deviation imitating the behaviour of the rotational energy response of synchronous generators. It is suggested a correct tuning of recovery droop controllers to avoid frequency extent drops or frequency overtime responses. In the same report it is mentioned that some control improvements can be done applying Wind Inertial Control (WIC) and Wind Frequency Droop (WFD). Reference [45] presents a method called Fast Power Reserve (FPR) based synthetic inertia, which is able to extract the extra power from the rotor up to $10 \%$ of actual power.

The incorporation of synthetic inertia has also been studied in the Nordic system in [46], where wind turbines have been equipped with synthetic inertia supplementary control. Due to the presence of synthetic inertia the minimum frequency raises however the recovery is delayed. The authors suggest to study and develop control algorithms to avoid the delay and analyse the contribution of small wind turbines.

\section{CASE STUDIES}

Fig. 2 shows the single-line diagram of the Nordic test system presented in [47]. This system contains 32 high voltage buses. The transmission system is designed for $400 \mathrm{kV}$ with some regional systems at $220 \mathrm{kV}$ and $130 \mathrm{kV}$. The simulation of this test system has been performed by the software SIMPOW $^{\circledR}[48]$.

Fig. 3 shows the dynamic response of the system frequency after disconnection of generator G8 with $P_{G 8}=850$ (MW). In the figure, the frequency nadir (in green), the maximum dynamic frequency deviation (in cyan) and the post-disturbance steady state frequency deviation (in purple) are also indicated.

Fig. 4 shows the system frequency response (in blue) and the RoCoF (in green). In the zoom in, it can be seen that after the initial transient process (after approximately two seconds) the frequency falls at an almost constant rate of approximately $0.12(\mathrm{~Hz} / \mathrm{s})$ then the generation involved in the primary control starts to increase its production to compensate the loss, however there is a steady state error remained.

In equation (4), the power change is given by

$$
\Delta P=-850+\alpha
$$

where $\alpha$, is a positive constant due to the voltage and frequency decency of the loads.

Setting $\alpha=0$, then the released kinetic energy can be estimated by

$$
S H=\Delta P \cdot \frac{f_{0}}{2 \cdot \frac{d f}{d t}}=-850 \frac{50}{2 \cdot(-0.12)}=177(\mathrm{GWs})
$$

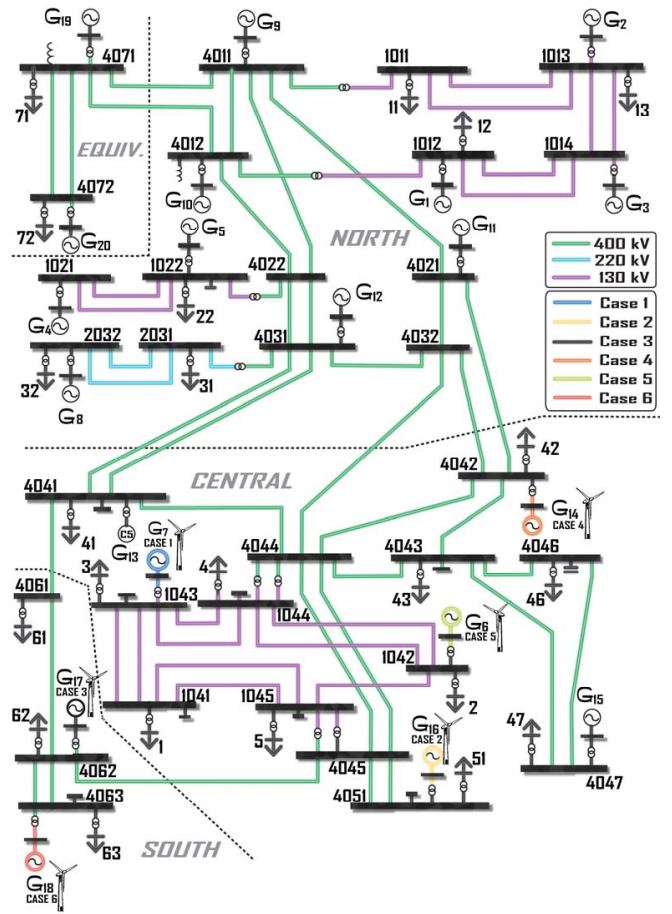

Fig. 2 The Nordic test system

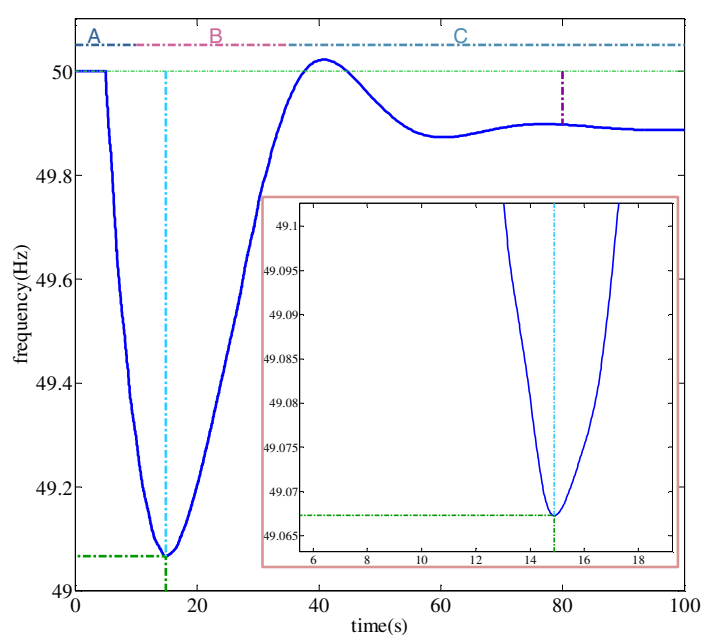

Fig. 3 The system frequency variation after tripping $G_{8}$

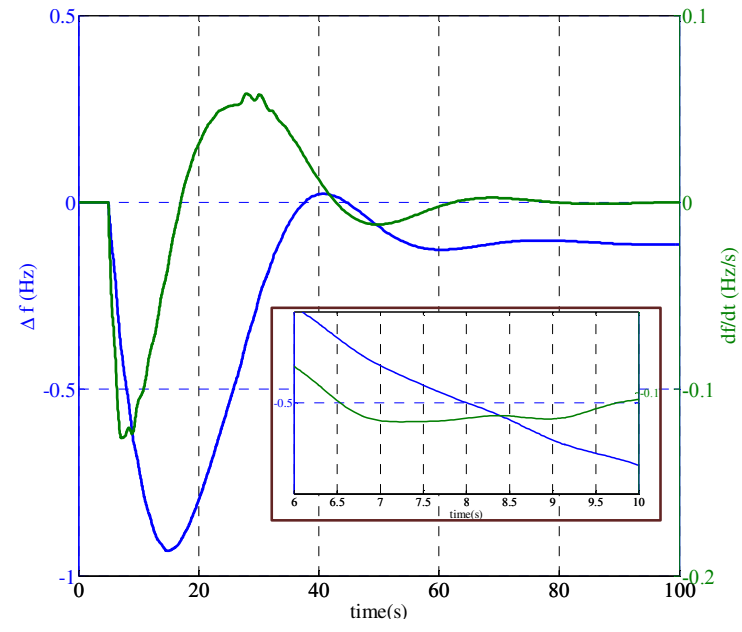

Fig. 4 The system frequency variation and ROCOF 
In Table I, some relevant metrics for this disturbance (base case) are summarized.

\begin{tabular}{lc}
\multicolumn{2}{c}{ TABLE I. SOME RELEVANT METRICS IN BASE CASE } \\
\hline \hline METRIC & VALUE \\
\hline FREQUENCY NADIR (Hz) & 49.06 \\
\hline FREQUENCY NADIR TIME (s) & 9.88 \\
\hline MAXIMUM FREQUENCY DEVIATION $(\mathrm{Hz})$ & 0.92 \\
\hline STEADY STATE FREQUENCY DEVIATION $(\mathrm{Hz})$ & 0.10 \\
\hline \hline
\end{tabular}

Next, the impact of the integration of wind power on the test system frequency response is analysed by replacing some of the synchronous generators with back-to-back converters with the same active and reactive power outputs. Note that the power outputs are fixed through the simulation.

Case 1 to Case 6 represent the replacement of synchronous generation by the integration of wind power through back to back converters gradually, in order to analyse different levels of wind power penetration, for example Case 1 considers the replacement of one generation only, and Case 2 considers the replacement of two generators including the one in Case 1, and so on. These six scenarios are summarised in Table II:

\begin{tabular}{ccccccc}
\multicolumn{1}{c}{ TABLE II. GENERATOR REPLACEMENT FOR EACH CASE } \\
\hline \hline CASE & 1 & 2 & 3 & 4 & 5 & 6 \\
\hline BUS & 1043 & 4051 & 4062 & 4042 & 1042 & 4063 \\
\hline GENERATOR & G7 & G16 & G17 & G14 & G6 & G18 \\
\hline \hline
\end{tabular}

Fig. 5 shows the time response of all cases when $\mathrm{G}_{8}$ is tripped. As shown in the figure the more synchronous generators are replaced by wind power turbines the larger dynamical frequency deviation becomes. A large frequency deviation may result in activating the protection systems of important components to be disconnected, and thereby leading to cascading failures in the system.

Table III shows the released kinetic energy (based equation (4)) by the remaining synchronous generators, and the ratio of wind power penetration with respect to the total generation for each case. Obviously, the released kinetic energy will decrease with higher wind power penetration.

\section{TABLE III. RELEASED KINETIC ENERGY} FOR EACH CASE

\begin{tabular}{ccc}
\hline \hline NO. & SH (GWS) & P(MW)\% \\
\hline CASE 1 & 167 & 1.2 \\
\hline CASE 2 & 160 & 5.4 \\
\hline CASE 3 & 156 & 9 \\
\hline CASE 4 & 149 & 13 \\
\hline CASE 5 & 144 & 15 \\
\hline CASE 6 & 131 & 20 \\
\hline \hline
\end{tabular}

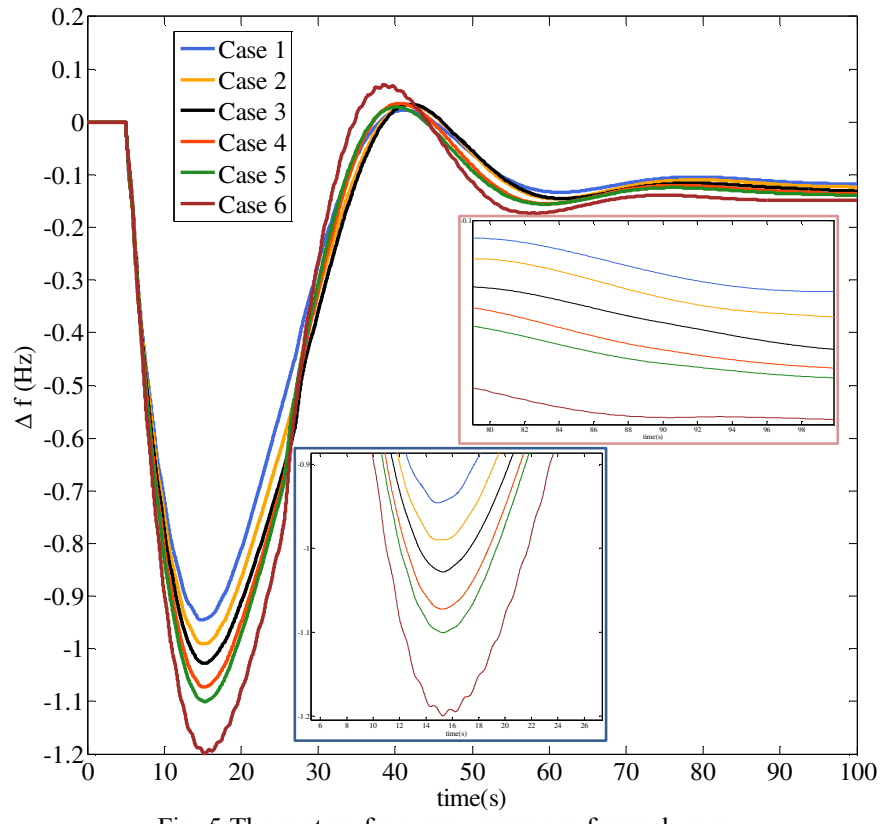

Fig. 5 The system frequency response for each case

The frequency nadir, RoCoF and the steady state frequency deviation of each case are given in Table IV.

TABLE IV. SOME RELEVANT METRICS FOR EACH CASE

\begin{tabular}{cccc}
\hline \hline NO. & $\begin{array}{c}\text { FREQUENCY } \\
\text { NADIR }\end{array}$ & ROCOF & $\begin{array}{c}\text { STEADY STATE FREQUENCY } \\
\text { DEVIATION }\end{array}$ \\
\hline CASE 1 & 49.06 & 0.127 & 49.9 \\
\hline CASE 2 & 49.02 & 0.132 & 49.89 \\
\hline CASE 3 & 48.98 & 0.136 & 49.88 \\
\hline CASE 4 & 48.93 & 0.142 & 49.88 \\
\hline CASE 5 & 48.9 & 0.147 & 49.87 \\
\hline CASE 6 & 48.8 & 0.161 & 49.86 \\
\hline \hline
\end{tabular}

The time response of RoCoF is shown in Fig. 6, where different waveforms and variability can be noticed. This is due to the different wind power penetration levels.

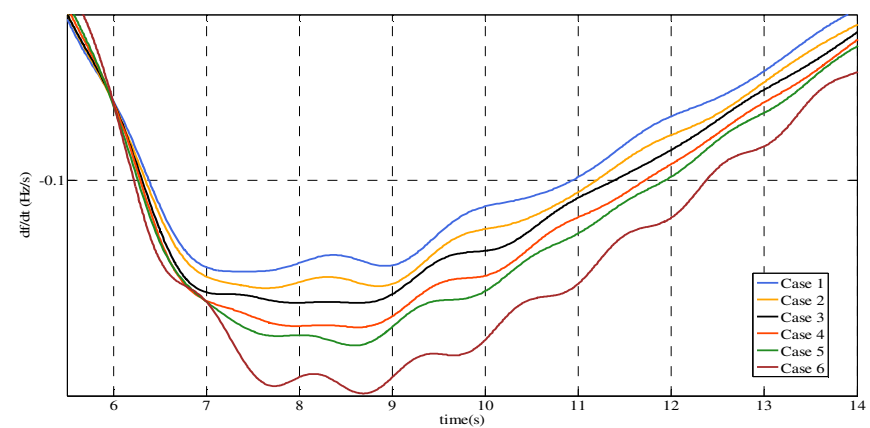

Fig. 6 RoCoF Time Response

\section{CONCLUSIONS}

An overview of the inertial and frequency response affected by the integration of wind power through back-to-back converters has been presented. The study results of some important reports have been discussed in this paper. In the presented reports, it has been shown that the high penetration of wind 
power has resulted in less system inertial response, and thereby larger dynamic system frequency deviation. The reports have also presented some methods to increase the system inertial response via a supplementary control known as synthetic inertia control.

To get insight in the obtained results in the presented references, and to understand the impact of the high penetration of wind power on the system dynamic response a test system, i.e. the Nordic test system, has been used. As an initial step of this research, the frequency response of the test system when replacing gradually all steam turbines with wind power has been studied. For this study some indexes, such the kinetic energy, RoCoF, the frequency nadir and the steady state frequency deviation, have been introduced. It has been observed that the obtained results have been very much similar to those presented in the references, i.e. the main impact of wind power without synthetic inertia control will be on RoCoF and the frequency nadir.

\section{FUTURE WORK}

Assuming we have access to the total production at all time the next step is to develop a method to estimate $\alpha$ in equation (5) which depends upon the load frequency and voltage dependency, and also the damping of the generators. Then equation (4) will be used to estimate the synthetic inertial response, and the obtained result will be compared with the actual result from simulation.

The impact of the reduced system inertial response on transient stability, small signal stability and voltage stability will be also studied.

A synthetic inertia control based FPR method will also be developed to deal with different operation levels and guarantying the frequency operation limits. This synthetic inertia should have the ability to increase the minimum frequency extracting the rotor energy and to avoid the delay in the frequency recovery as much as possible. Moreover, it is important to analyse the appropriate feedback signal to design the synthetic inertia control and the linear response of the RoCoF metric.

The addition of supplementary control loops to the power electronic interfaces will require an appropriate coordination method in order follow the wind variability and/or not interfere with other control targets, e.g. active and reactive power control, active power filtering or energy storage.

\section{REFERENCES}

[1] J.C. Smith, M.R. Milligan, E.A. DeMeo and B. Parsons, "Utility Wind Integration and Operating Impact State of the Art," IEEE Transactions on Power Systems, vol.22, no.3, pp.900-908, Aug. 2007

[2] V. Akhmatov and P.B. Eriksen, "A Large Wind Power System in Almost Island Operation-A Danish Case Study," IEEE Transactions on Power Systems, vol.22, no.3, pp.937,943, Aug. 2007

[3] H. Holttinen, M. O’Malley, J. Dillon, D. Flynn, A. Keane, H. Abildgaard and L. Soder, "Steps for a Complete Wind Integration Study," Hawaii International Conference on System Sciences, 7-10 Jan. 2013

[4] L. Li and W. Shiqian, "Investigation of the Strategy of Wind Farm Power Regulation Considering System Frequency Regulation Demand," 4th International Conference on Electric Utility Deregulation and Restructuring and Power Technologies, 6-9 July 2011
[5] M. Holmgren, L. Haarla, J. Matilainen and H. Holttinen, "Power Regulation Resources Required by Wind power in Finland and Regulation Characteristics of Power Plants," CIGRE/IEEE PES Joint Symposium Integration of Wide-Scale Renewable Resources Into the Power Delivery System, 29-31 July 2009

[6] I. Erlich and U. Bachmann, "Grid Code Requirements Concerning Connection and Operation of Wind Turbines in Germany, "IEEE Power Engineering Society General Meeting, 12-16 June 2005

[7] M. H. Bollen and F. Hassan, "Integration of Distributed Generation in the Power System". John Wiley \& Sons. Institute of Electrical and Electronics Engineers Press. Pp 7. 2011.

[8] G. Lalor, A. Mullane and M. O"Malley, "Frequency Control and Wind Turbine Technologies," IEEE Transactions on Power Systems, vol.20, no.4, pp. 1905,1913, Nov. 2005

[9] F. Gonzalez-Longatt, E. Chikuni, W. Stemmet and K. Folly, , "Effects of the Synthetic Inertia from Wind Power on the Total System Inertia after a Frequency Disturbance," Power Engineering Society Conference and Exposition in Africa, 9-13 July 2012

[10] J.F. Conroy and R. Watson, "Frequency Response Capability of Full Converter Wind Turbine Generators in Comparison to Conventional Generation," IEEE Transactions on Power Systems, vol.23, no.2, pp.649,656, May 2008

[11] S. Yuan-Zhang, Z. Zhao-Sui, L. Guojie and L. Jin, "Review on Frequency Control of Power Systems with Wind Power Penetration," International Conference on Power System Technology, 24-28 Oct. 2010

[12] Z.S. Zhang, Y.Z. Sun, J. Lin and G.J. Li, "Coordinated Frequency Regulation by Doubly Fed Induction Generator-based Wind Power Plants," IET Renewable Power Generation, vol.6, no.1, pp.38,47, January 2012

[13] NERC IVGTF Task 2.4 Report: "Operating Practices, Procedures and Tools"

[14] EWEA, "Large Scale Integration of Wind Energy in the European Power Supply"

[15] J. Brisebois and N. Aubut, "Wind Farm Inertia Emulation to Fulfill Hydro-Québec's Specific Need," Power and Energy Society General Meeting, 24-29 July 2011

[16] J. Conto, "Grid Challenges on High Penetration Levels of Wind Power," IEEE Power and Energy Society General Meeting, 22-26 July 2012

[17] S. Sharma, H. Shun-Hsien and N.D. Sarma, "System Inertial Frequency Response Estimation and Impact of Renewable Resources in ERCOT Interconnection," Power and Energy Society General Meeting, 2011

[18] N.W. Miller, M. Shao, S. Venkataraman, C. Loutan, M. Rothleder, "Frequency Response of California and WECC Under High Wind and Solar Conditions," Power and Energy Society General Meeting, 22-26 July 2012

[19] H. Shun-Hsien, D. Maggio, K. McIntyre, V. Betanabhatla, J. Dumas and J. Adams, "Impact of Wind Generation on System Operations in the Deregulated Environment: ERCOT Experience," Power \& Energy Society General Meeting, 26-30 July 2009

[20] E. Muljadi, V. Gevorgian, M. Singh, S. Santoso, "Understanding Inertial and Frequency Response of Wind Power Plants," Power Electronics and Machines in Wind Applications, July 2012

[21] L. Meegahapola, and D. Flynn, "Impact on Transient and Frequency Stability for a Power System at Very High Wind Penetration," Power and Energy Society General Meeting, 25-29 July 2010

[22] J. Morren, S. W. De Haan, and J.A. Ferreira, "Primary Power/Frequency control with Wind Turbines and Fuel Cells," Power Engineering Society General Meeting, 2006.

[23] H. Chavez, R. Baldick, and S. Sharma, "Regulation Adequacy Analysis Under High Wind Penetration Scenarios in ERCOT Nodal," IEEE Transactions on Sustainable Energy, vol.3, no.4, pp.743,750, Oct. 2012

[24] P. Kundur, J. Paserba, V. Ajjarapu, G. Andersson, A. Bose, C. Canizares, N. Hatziargyriou, D. Hill, A. Stankovic, C. Taylor, T. Van Cutsem, V. Vittal, " IEEE/CIGRE Joint Task Force on Stability Terms and Definitions," IEEE Transactions on Power Systems, vol.19, no.3, pp. 13871401, Aug. 2004

[25] I. Egido, F. Fernandez-Bernal, L. Rouco, "Evaluation of Automatic Generation Control (AGC) Regulators by Performance Indices Using Data from Real Operation," IET Generation, Transmission \& Distribution, vol.1, no.2, pp.294-302, March 2007

[26] A. P. Tennakoon, A. Arulampalam, J.B. Ekanayake, S.G. Abeyratne and A. Alahakoon, "Operational Restrictions with Maximum Power Extrac- 
tion of DFIG Connected Wind Farms," IEEE International Conference on Sustainable Energy Technologies, Nov. 2008

[27] R. P. Chandrasena, A. Arulampalam, J.B. Ekanayake and S.G. Abeyratne, "Grid Side Converter Controller of DFIG for Wind Power Generation," International Conference on Industrial and Information Systems, 9-11 Aug. 2007

[28] R. Cardenas, R. Pena, S. Alepuz and G. Asher, "Overview of Control Systems for the Operation of DFIGs in Wind Energy Applications," IEEE Transactions on Industrial Electronics, vol.60, no.7, pp.2776,2798, July 2013

[29] K. Elkington, H. Latorre, and M. Ghandhari, "Operation of Doubly Fed Induction Generators in Power Systems with VSC-HVDC Transmission," IET International Conference on AC and DC Power Transmission, 19-21 Oct. 2010

[30] X. Lie, "Coordinated Control of DFIG's Rotor and Grid Side Converters During Network Unbalance," IEEE Transactions on Power Electronics, vol.23, no.3, pp.1041,1049, May 2008

[31] A. Abdel-Khalik, A.M. Massoud, A.A. Elserougi and S. Ahmed, "Optimum Power Transmission-Based Droop Control Design for MultiTerminal HVDC of Offshore Wind Farms," IEEE Transactions on Power Systems, vol.PP, no.99, pp.1,9, 2013

[32] L. Jun, J. Tianjun, O. Gomis-Bellmunt, J. Ekanayake, N. Jenkins, "Operation and Control of Multiterminal HVDC Transmission for Offshore Wind Farms," IEEE Transactions on Power Delivery, vol.26, no.4, pp.2596,2604, Oct. 2011

[33] M. Zhixin, F. Lingling, D. Osborn, and S. Yuvarajan, "Wind Farms with HVDC Delivery in Inertial Response and Primary Frequency Control," IEEE Transactions on Energy Conversion, vol.25, no.4, pp.1171,1178, Dec. 2010

[34] NERC Frequency Response Initiative Report, October, 2012.

[35] P. W. Christensen and G. C. Tarnowski, "Inertia for Wind Power Plants - state of the art review ", 10th International Workshop on Large-Scale Integration of Wind Power into Power Systems as well as on Transmission Networks for Offshore Wind Farms, Aarhus, Denmark, 2011.

[36] J. Björnstedt, Integration of Non-synchronous Generation Frequency Dynamics, Doctoral Dissertation Lund University 2012

[37] P. Tielens and D. Van Hertem, "Grid Inertia and Frequency Control in Power Systems with High Penetration of Renewables.”, available online.

[38] F. Abbaspourtorbati, M. Scherer, A. Ulbig, G. Andersson, "Towards an Optimal Activation Pattern of Tertiary Control Reserves in the Power System of Switzerland," American Control Conference, 27-29 June 2012

[39] J. Zhu, C. D. Booth, G. P. Adam, A. J. Roscoe and C. G. Bright, "Inertia Emulation Control Strategy for VSC-HVDC Transmission Systems," IEEE Transactions on Power Systems, vol.PP, no.99, pp.1,11, 2012

[40] L. Wu and D.G. Infield, "Towards an Assessment of Power System Frequency Support From Wind Plant-Modeling Aggregate Inertial Response," IEEE Transactions on Power Systems, vol.PP, no.99, pp.1,1, 2013

[41] G. Delille, B. Francois and G. Malarange, "Dynamic Frequency Control Support: A Virtual Inertia Provided by Distributed Energy Storage to Isolated Power Systems," Innovative Smart Grid Technologies Conference Europe, 11-13 Oct. 2010

[42] M. F. Arani and E. F. El-Saadany, "Incorporating DFIG based Wind Power Generation in Microgrid Frequency Regulation," Power and Energy Society General Meeting, 22-26 July 2012

[43] R.G. de Almeida and, J.A. Pecas Lopes, "Participation of Doubly Fed Induction Wind Generators in System Frequency Regulation," IEEE Transactions on Power Systems, vol.22, no.3, pp.944,950, Aug. 2007

[44] Aho, J.; Buckspan, A.; Laks, J.; Fleming, P.; Yunho Jeong; Dunne, F.; Churchfield, M.; Pao, L.; Johnson, K., "A Tutorial of Wind Turbine Control for Supporting grid frequency through active power control," American Control Conference (ACC), 2012, NREL Report June 2012

[45] T. Knüppel, P. Thuring, S. Kumar, M.N. Kragelund, R. Nielsen, K. André, "Frequency Activated Fast Power Reserve for Wind Power Plant Delivered from Stored Kinetic Energy in the Wind Turbine Inertia."

[46] M. Seyedi and M. Bollen, The Utilization of synthetic Inertia from Wind Farms and its Impact on Existing Speed Governors and System Performance. Part 2 Report of Vindforsk Project V-369. Elforsk rapport 13:02. Jan. 2013

[47] Cigre Task Force 38.02.08, "Long Term Dynamics Phase II Final Report", Cigre March 1995
[48] Manitoba HVDC Research Center, "SIMPOW," 2013. [Online]. Available: http://simpow.com/

Harold Chamorro ( $\left.\mathrm{S}^{\prime} 07\right) \mathrm{He}$ is electrical engineer (2009) and Master of Science in electrical engineering from Universidad de los Andes (Bogotá, Colombia). He is currently a member of the Electric Power System Department at Royal Institute of Technology (KTH), where he is working towards a Ph.D. degree.

Mehrdad Ghandhari (M'00) received the M.Sc. and Ph.D. degrees in electrical engineering from Royal Institute of Technology (KTH), Stockholm, Sweden, in 1995, and 2000, respectively. He is currently a full Professor at $\mathrm{KTH}$. His research interests include power system dynamics, stability and control, and FACTS and HVDC systems.

Robert Eriksson (S'02) received his M.Sc., Tech. Lic. and Ph.D. degrees in Electrical Engineering from KTH Royal Institute of Technology, Stockholm, Sweden, in 2005, 2008 and 2011 respectively. Currently, he is a postdoctoral researcher in the Division of Electric Power Systems, KTH Royal Institute of Technology. His research interests include power system dynamics and stability, HVDC systems, DC grids and automatic control. 